From 28 June to 2 July 1971 the German island town of Lindau in Lake Constance close to the Austrian and Swiss borders was host to a gathering of illustrious men of science when, for the 21st time, Nobel Laureates held their reunion there.

The success of the first Lindau reunion (1951) of Nobel Prize winners in medicine had inspired the organizers to invite the chemists and the physicists in turn in subsequent years. After the first three-year cycle it was decided to let students and young scientists also attend the meetings so they could encounter these eminent men on an informal and personal level. For the Nobel Laureates too the Lindau gatherings soon became an agreeable occasion for making or renewing acquaintances with their contemporaries, untrammelled by the formalities of the Stockholm ceremony and unrestricted by the narrow limits of the conventional scientific conference. Their lectures at Lindau do not have to present anything fundamentally new in science but illustrate chosen aspects of their work including their attitudes to its wider social implications. They are at the same time freely accessible to the new generation of thinkers and researchers.

\section{The 7th Reunion of Physicists}

The following Nobel Prize holders came to Lindau this summer, all physicists except where stated otherwise ; the year is that of their award : Hannes Alfvén

Walter H. Brattain

Adolf Butenandt (Chemistry)

Paul A. M. Dirac

Manfred Eigen (Chemistry)

Werner Forssmann (Medicine)

Ragnar Frisch (Economics)

Maria Goeppert Mayer

Werner Heisenberg

Robert Hofstadter

J. Hans D. Jensen

Alfred Kastler

Willis E. Lamb

Willard F. Libby (Chemistry)

Edwin M. McMillan (Chemistry)

Rudolf L. Mössbauer

Isidor I. Rabi

Charles H. Townes

Ernest T.S. Walton

Eugene $P$. Wigner

1970

1956

1939

1933

1967

1956

1969

1963

1932

1961

1963

1966

1955

1960

1951

1961

1944

1964

1951

1963

Among those absent owing to illness or last-minute commitments were Murray Gell-Mann, Donald A. Glaser, Tsung-Dao Lee and the USSR physicists Nikolai G. Basov, Ilya M. Frank and A. M. Prokhorov.

Altogether over 400 students and young scientists attended: 325 from Germany, 40 from France and smaller groups from Austria, Switzerland and

\title{
Nobel Prize Physicists meet at Lindau
}

\section{W. S. Newman}

the United Kingdom, and an audience of more than 500 from 8 countries daily filled the elegant Stadtheater. The programme consisted of a number of lectures in the mornings, two social functions, a platform discussion, an informal reunion between students and Nobel Laureates and, on the last day, the traditional steamer excursion on Lake Constance to the island of Mainau belonging to Count Bernadotte, the patron of the reunion.

In most lectures, even if devoted to experimental developments, the speakers succeeded in conveying how their work had furthered man's quest for knowledge about the universe and how this knowledge could help to shape the future of society.

\section{Investigating our Universe}

The nature of the interstellar medium was the subject of Townes' talk. In regions where infrared and microwave techniques have only lately pierced the dense dust clouds, simple organic molecules have been detected and one could speculate about life originating from these interstellar substances, although many facts speak against such assumptions.

Astrophysical implications were evident in the effects Kastler considered when treating the behaviour of atoms in strong fields of electromagnetic radiation, and were also discussed by Lamb when he dealt with the highly excited states of the helium atom. Describing the latest detectors developed for high-energy physics, Hofstadter bridged the gap between particle measurement as practised on earth, using large accelerators as source, and cosmic shower investigations by means of astronomical observatories in outer space.

Cosmic rays indirectly help us to unravel the timetable of the recent history of our planet. Libby, the inventor of the technique of radiocarbon dating, talked about a method of calibration using tree-ring and sediment data, which eliminates some puzzling discrepancies in fixing the dates of historical events. These deviations in the radiocarbon time scale are due to changes in incident cosmic radiation (producing the carbon isotopes) brought about by variations in the geomagnetic field.

Thus chemistry may reveal mankind's remote past whereas its longterm future could well be shaped by the developments mentioned by Mössbauer, viz. new techniques for analysing crystal structures to be used in studying the most complex of crystals, the proteins, with far-reaching consequences on the development of biological sciences.

Illustrating his review of 60 years of molecular beams with many personal reminiscences $R a b i$ looked back nostalgically towards his early days in physics not all that long ago, when few formalities were needed to move from one leading research centre to another. Apparatus was simple and cheap and administrative problems were minimal; the results achieved, however, proved to be of profound and lasting consequence. Now facilities have increased enormously and the saying 'Life is a timeconsuming and expensive business ' could well be applied to science.

His belief in physics as the central core of knowledge of our universe was unshaken : it provides the tools for all other research.

\section{Science, God and Politics}

Much that started with physics has ended with chemistry, but with modern physics we often find ourselves in the realms of philosophy. Dirac guided us there in characteristic style in his talk on fundamental problems in physics. To the basic questions

1) Is there causality?

2) Are space and time continuous ?

3) Is there an ether? quantum mechanics gave some answers and proved valid for low-energy problems. In order to deal with high energies and very small objects drastic changes in the foundations of physics are required, such as Heisenberg brought about in the twenties. 


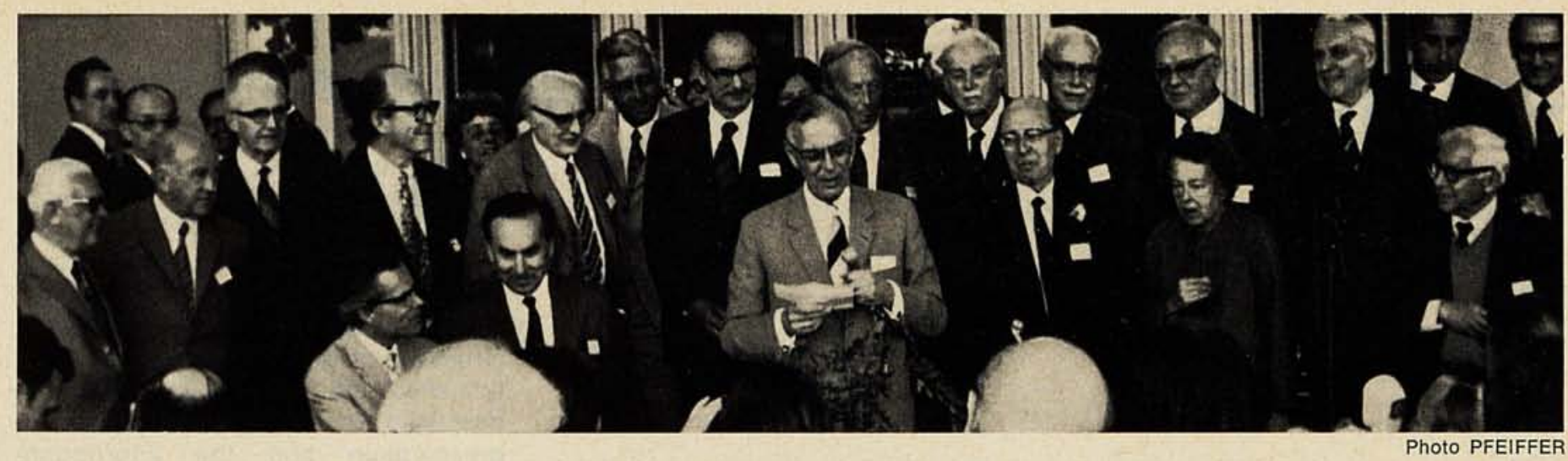

Different answers to the basic questions may be needed and a new mathematics will have to serve as the basis for a complete theory of physics. Finally he added a fourth question: Is there a God? and attempted to answer it as a physicist. If there is causality, there is no need for God and a definite answer to the question may be obtained by considering the origin of life in the universe. If the chances for life to start were found to be excessively small, divine intervention would be necessary - a thought-provoking confrontation of science with theology presented in inimitable style by one of whom it was said: There is no God and Dirac is his prophet.

Where heavy expenditure is involved, political questions must be faced even by the purest of scientists. In an eagerly awaited talk on the aspects of physics and science policy that enter into the planning of large particle accelerators, Heisenberg reviewed the development of high-energy physics and agreed that, early on, new insight had been gained thanks, to the provision of larger machines. Since then, however, experimental results and theoretical considerations had convinced him that, to continue expanding the size of accelerators at great cost, would not yield a commensurate return and so he became known as an outright opponent of the original Super-CERN project. Nevertheless, successful international collaboration, as exemplified by CERN, is an important factor, and when a revised scheme was proposed for a cheaper accelerator using more modern techniques and located near the existing laboratory, he could no longer oppose such a step in view of the wide support given to it by the European physics community. Politicians needed the impartial advice of scientists to help them decide the financial and social questions posed by big science. It was heartening to find the British high-energy physicists willing to participate in the new project while being prepared to meet the added expenditure by sacrifices in their national programme. Concentration of experimental facilities at CERN avoided the risk of causing a science 'population explosion', although a more evén distribution of research centres in Europe remains desirable. The CERN decision was a good solution and a fruitful compromise.

Closer contacts between scientists and politicians were also envisaged by Frisch, the founder of the scientific discipline of econometrics. Governments should be helped to formulate the aims of their economic policy, and perhaps even their scientific one, in precise terms capable of being handled by computer. A socalled preference function defining the aims could be established from the politicians' answers to a systematically prepared set of interview questions. The social, economic or scientific development programme would then be worked out by computer, to serve, after further discussions, as a basis for a realistic policy.

These glimpses of a science-guided and computer-controlled government of the future were a timely reminder of the growing responsibility the scientist has towards society as a whole. As Alfvén pointed out in his talk on the Pugwash Movement whose president he has recently become, it is necessary to clarify the political and social consequences of scientific research and enable statesmen to minimize any resultant dangers. Scientists were morally responsible for the application of their work although not always fully aware of its implications. The aim must be the welfare and not the warfare of mankind.

\section{The Students have their Say}

For the public discussion the three speakers who had touched on political problems, viz. Heisenberg, Frisch and Alfvén, shared the platform with three young scientists and faced their questions and those of the audience. The spirit of contest-
From left to right: (front row) R. L. Mössbauer, R. Hotstadter, Count Bernadotte, E. P. Wigner, Maria Goeppert-Mayer, I. I. Rabi ; (second row) A. Butenandt, W. Heisenberg, E. T. S. Walton, W. F. Libby, J. H. D. Jensen, E. M. McMillan, H. Alfvén, P. A. M. Dirac, W. H. Brattain, W. Forssmann, R. Frisch.

ation that had already manifested itself - albeit softly - during the official opening speeches of the Meeting, could now be voiced in more precise terms. Heisenberg undoubtedly was the main target. Why had he changed his attitude on the big accelerator - how could such enormous expenditure be justified in view of other, more urgent, demands of science and society - why such emphasis on fundamental research to satisfy relatively few scientists was European competition with the already existent or planned giant accelerators in the USA and USSR really necessary? Heisenberg reiterated his arguments and pointed out the basic importance to all other sciences of the fundamental knowledge acquired in elementary particle physics. The CERN decision had to be a political one and, as such, to be a compromise; in any case the benefits of successful international cooperation were incalculable. In this discussion the differences in attitudes more than one generation apart became very evident.

Alfvén had to counter accusations that Pugwash had proved ineffective because it was little known. But even if its methods were considered inadequate, at least its programme appeared to meet with the approval of the young.

Much calmer spirits prevailed during the outing by steamer on the last day, matching the still waters of the lake (but not the hazy air above it) when, small knots of enquiring minds surrounded the Nobel Laureates on or below deck and much useful information was imparted. Count Bernadotte said farewell on his sub-tropical island and, like many of his listeners, looked forward to the next physicists' reunion in 1974 . 